Check for updates

Cite this: Phys. Chem. Chem. Phys., $2018,20,19447$

Received 7th March 2018, Accepted 29th June 2018 DOI: $10.1039 / c 8 c p 01505 h$

rsc.li/pccp

\section{Thermal reduction of ceria nanostructures on rhodium(111) and re-oxidation by $\mathrm{CO}_{2} \dagger$}

\author{
Andreas Schaefer, (D) *ab Benjamin Hagman, ${ }^{\text {b }}$ Jan Höcker, ${ }^{\text {cd }}$ Uta Hejral, ${ }^{\text {b }}$ \\ Jan Ingo Flege $\mathbb{D}^{\mathrm{cd}}$ and Johan Gustafson ${ }^{\mathrm{b}}$
}

\begin{abstract}
The thermal reduction of cerium oxide nanostructures deposited on a rhodium(111) single crystal surface and the re-oxidation of the structures by exposure to $\mathrm{CO}_{2}$ were investigated. Two samples are compared: a rhodium surface covered to $\approx 60 \%$ by one to two $\mathrm{O}-\mathrm{Ce}-\mathrm{O}$ trilayer high islands and a surface covered to $\approx 65 \%$ by islands of four $\mathrm{O}-\mathrm{Ce}-\mathrm{O}$ trilayer thickness. Two main results stand out: (1) the thin islands reduce at a lower temperature $(870-890 \mathrm{~K})$ and very close to $\mathrm{Ce}_{2} \mathrm{O}_{3}$, while the thicker islands need higher temperature for reduction and only reduce to about $\mathrm{CeO}_{1.63}$ at a maximum temperature of $920 \mathrm{~K}$. (2) Ceria is re-oxidized by $\mathrm{CO}_{2}$. The rhodium surface promotes the re-oxidation by splitting the $\mathrm{CO}_{2}$ and thus providing atomic oxygen. The process shows a clear temperature dependence. The maximum oxidation state of the oxide reached by re-oxidation with $\mathrm{CO}_{2}$ differs for the two samples, showing that the thinner structures require a higher temperature for re-oxidation with $\mathrm{CO}_{2}$. Adsorbed carbon species, potentially blocking reactive sites, desorb from both samples at the same temperature and cannot be the sole origin for the observed differences. Instead, an intrinsic property of the differently sized $\mathrm{CeO}_{x}$ islands must be at the origin of the observed temperature dependence of the re-oxidation by $\mathrm{CO}_{2}$.
\end{abstract}

\section{Introduction}

The oxides of cerium are essential materials in the chemical industry. ${ }^{1,2}$ They are mainly employed as support for metal nanoparticles in heterogeneous catalysis facilitating the oxidation of poisonous $\mathrm{CO}$ and removal of nitric gases from, for example, automotive exhaust. The role of cerium oxide, however, exceeds the one of a bare oxide support. Cerium's capability to easily switch between the $\mathrm{Ce}^{3+}$ and $\mathrm{Ce}^{4+}$ oxidation state results in a high oxygen mobility and storage capacity of the oxide. Hence, catalysts based on cerium oxide have, for example, also been of increasing interest for soot oxidation in the exhaust of diesel engines. ${ }^{3}$ In recent years, research has yielded a number of ceria based model catalyst systems that can potentially play an essential role in the future. Especially in

\footnotetext{
${ }^{a}$ Department of Chemistry and Chemical Engineering - Competence Centre for Catalysis, Chalmers University of Technology, Gothenburg, 412 96, Sweden. E-mail: andreas.schaefer@chalmers.se

${ }^{b}$ Division of Synchrotron Radiation Research, Lund University, Box 118, SE-221 00 Lund, Sweden

${ }^{c}$ Institute of Solid State Physics, University of Bremen, Otto-Hahn-Allee 1, D-28359 Bremen, Germany

${ }^{d}$ MAPEX Institute for Materials and Processes, University of Bremen, D-28359 Bremen, Germany

$\dagger$ Electronic supplementary information (ESI) available: Low energy electron diffraction and scanning tunneling microscopy data. Additional photoelectron spectra of the O 1s, C 1s, Rh 3d, and Ce 4d levels. See DOI: 10.1039/c8cp01505h
}

light of the challenges we are facing in terms of energy generation and storage, and increasing levels of atmospheric $\mathrm{CO}_{2}$, research and development of new materials and concepts is crucial, including research providing a basic understanding of the mechanisms at play on an atomic scale. By studying cerium oxide thin films and nanostructures supported on metal surfaces, so-called inverse cataylsts, ${ }^{4,5}$ interesting model systems for important reactions could be realized, that can potentially exceed the performance of materials currently employed industrially. Examples for such reactions are the water-gas shift, alcohol reforming, $\mathrm{CO}_{2}$ hydrogenation to methanol, and methane activation, to name a few. ${ }^{6}$

A prominent example that has received considerable attention is the synthesis of methanol from $\mathrm{CO}_{2}$ and $\mathrm{CO}$ over $\mathrm{Cu} / \mathrm{ZnO}$ based catalysts. The structure and composition in the active state of the catalyst has been debated, but recent results show that a $\mathrm{ZnO}$ layer forms on top of the metal particles of a real catalyst generating a metal-oxide interface that is crucial for the reaction. ${ }^{7}$ This strong metal support interaction (SMSI) forming the oxide layer not only affects the structure of the metal particle but also generates a synergistic effect that drives the reaction. ${ }^{8-10}$ Furthermore, ceria structures on copper have been shown to achieve even higher turnover rates than the $\mathrm{ZnO} / \mathrm{Cu}$ system. ${ }^{11}$ These results are a strong motivation for the study of inverse configurations, as they might be of importance also in other catalytic systems in the active state. The interaction of ceria surfaces with $\mathrm{CO}_{2}$ has been investigated both on powder 
supports and model surfaces. Studies on powder catalysts show that a partially reduced cerium oxide support can be re-oxidized by $\mathrm{CO}_{2}$ to $\mathrm{CeO}_{1.8-1.9 \cdot}{ }^{12,13}$ The oxygen is supplied by the dissociation of $\mathrm{CO}_{2}$ at sites on the metal particles and $\mathrm{Ce}^{3+}$ sites in reduced ceria. ${ }^{14}$ A study on a $\mathrm{CeO}_{x}(111)$ film by Lykhach et al., however, revealed that neither the presence of a transition metal nor hydroxyl groups is required for the re-oxidation of ceria up to $\mathrm{CeO}_{1.90}$ to take place, even at room temperature. ${ }^{15} \mathrm{It}$ has to be noted that, while the re-oxidation of the oxide has been observed in case of the (111) oriented surface, the (100) and (110) surfaces of $\mathrm{CeO}_{2-x}$ have been shown to not be re-oxidized by adsorbed $\mathrm{CO}_{2},{ }^{16,17}$ though exhibiting a strong interaction with $\mathrm{CO}_{2}$ at low temperature.

Many transition metal surfaces have been employed for the growth of ceria films and structures, of which the three most studied are $\mathrm{Ru}(0001), \mathrm{Cu}(111)$, and $\mathrm{Pt}(111)$. The growth on several substrates has recently been reviewed by Rodriguez et $a .^{6}$ and preparation methods as well as the surface chemistry of ceria have been reviewed by Mullins. ${ }^{16}$ Rhodium is a transition metal relevant in heterogeneous catalysis, and few studies ${ }^{18-22}$ have dealt with ceria films prepared on it. Like on many other transition metal surfaces, cerium oxide films on $\mathrm{Rh}(111)$ can either be grown by reactive physical vapor deposition (RPVD), i.e. evaporation of cerium metal in an oxygen ambient, ${ }^{18}$ or by deposition of cerium metal onto the substrate and post-annealing in oxygen. ${ }^{20}$ It has been demonstrated that the oxide grows in double layers, with one layer being a O-Ce-O tri-layer, and that films of higher thickness are thermally more stable up to $900-1073 \mathrm{~K}^{18,20}$ After preparation, the oxide films are reported to possess a stoichiometry close to $\mathrm{CeO}_{2}$ with a $\mathrm{Ce}^{3+}$ content of only a few percent, while thin films are found to exhibit a higher $\mathrm{Ce}^{3+}$ content, ${ }^{22,23}$ probably due to the proximity to the metal substrate. ${ }^{24}$ A question we address with this study is to what extent the difference in reducibility between thin and thick films/islands is reflected in the re-oxidation behavior. In a recent study Grinter et al. showed that ceria islands, which had previously been reduced using a focused X-ray beam, can be re-oxidized by oxygen chemisorbed on the $\mathrm{Rh}(111)$ support once the oxygen becomes mobile above $400 \mathrm{~K}^{21}$

In this article we show that the latter effect can be exploited by using the reactivity of the Rh surface at elevated temperatures to split the $\mathrm{CO}_{2}$ molecule. Operando XPS measurements in the high-vacuum range $\left(10^{-5} \mathrm{hPa}\right)$ reveal that chemisorbed oxygen and CO are generated during the reaction and that the adsorbed oxygen atoms can then re-oxidize reduced ceria islands. Not surprisingly, this effect is the most effective above the desorption temperature of CO. The results, however, further reveal a temperature dependence of the re-oxidation process that does not depend on the adsorbate coverage, but on the thickness of the ceria islands.

\section{Experimental}

\subsection{Sample preparation}

The $\mathrm{Rh}(111)$ single crystals (Surface Preparation Laboratory) were cleaned by cycles of $\mathrm{Ar}^{+}$sputtering (1-1.5 keV, $\left.20 \mathrm{~min}\right)$ and annealing (up to $1570 \mathrm{~K}$ ), including an annealing step in $1 \times 10^{-6}$ mbar oxygen to remove carbon impurities. The sample surface was considered clean when the signals of C KLL and O KLL emissions were below the detection limit in Auger electron spectroscopy (AES). Additionally, the surfaces were checked by scanning tunneling microscopy (STM) and low energy electron diffraction (LEED) prior to the oxide deposition. The $\mathrm{CeO}_{2}$ films were prepared by reactive physical vapor deposition (RPVD), i.e. evaporation of Ce metal from a Mo crucible by an electron beam evaporator (EFM3, FOCUS GmbH) in an oxygen background pressure of $1.3 \times 10^{-7} \mathrm{hPa}$. The growth rate was about $0.4 \AA \mathrm{min}^{-1}$. The substrate temperatures were chosen to be $1030 \mathrm{~K}$ and $830 \mathrm{~K}$ to control the island sizes. As has been shown for different metal surfaces, a higher substrate temperature initially leads to larger $\mathrm{CeO}_{2}$ structures, which then quickly grow in height rather than to wet the metal surface. ${ }^{25,26}$ A lower growth temperature, on the other side, leads to the growth of a larger number of smaller islands. In fact, it has been shown that continuous $\mathrm{CeO}_{2}$ films with only a few open layers can be prepared by starting the deposition at lower substrate temperature and increasing the temperature slowly during growth. ${ }^{27}$

The amount of deposited material was determined by evaluating the attenuation of the Rh KLL signal at $300 \mathrm{eV}$ electron energy in AES, assuming an inelastic mean free path of $7.6 \AA$ for the calculation (determined following ref. 28). Together with information from STM we were then able to estimate the total amount of deposited material in monolayer equivalent (MLE) with one monolayer referring to the height of a O-Ce-O trilayer in the [111] direction of the $\mathrm{CeO}_{2}$ bulk unit cell (3.12 $\left.\mathrm{A}\right)$.

After preparation, the samples were characterized by AES, STM and LEED before they were taken out of the vacuum chamber and packed in evacuated containers for transport. Hence, the samples were exposed to atmosphere for about 30-40 min in total (including the time needed to mount the samples again). After the samples have been transferred into the vacuum chamber at beamline 9.3.2 at the ALS, spectra were measured before a cleaning procedure was applied. The cleaning procedure consisted of heating the sample to $870 \mathrm{~K}$ in $1.3 \times 10^{-5} \mathrm{hPa}$ oxygen. This procedure removes all carbon contamination. Spectra of the as-transferred and clean surface are compiled in Fig. S3 in the ESI. $\dagger$

\subsection{Photoelectron spectroscopy}

The reduction and re-oxidation experiments were carried out at the soft X-ray AP-XPS beamline 9.3.2 at the Advanced Light Source in Berkeley, CA, USA. ${ }^{29}$ The photons originate from a bending magnet and the end-station is housing a Scienta R4000 HiPP system for operando studies in a pressure up to several hPa. The available photon energy at this beamline ranges from 200 to $900 \mathrm{eV}$, which renders the Ce $3 \mathrm{~d}$ levels unavailable for the measurement. Furthermore, also the oxidation state sensitive resonant enhancement of the Ce $4 \mathrm{f}$ and $\mathrm{O} 2 \mathrm{p}$ emission in the valence band when exciting with photon energies of the Ce $\mathrm{N}_{\mathrm{IV}, \mathrm{V}}$ transition, ${ }^{30-32}$ in the range of $121-125 \mathrm{eV}$, is not available in the photon energy range provided by the beamline. Hence we measured the Ce $4 \mathrm{~d}$ levels to determine the oxide's 
stoichiometry. The procedure is described in detail in the ESI. $\dagger$ We tested for beam induced reduction by measuring Ce $4 \mathrm{~d}$ spectra continuously for $30 \mathrm{~min}$ but could not detect any decrease of the $\mathrm{Ce}^{4+}$-related signal. This is in line with studies of ceria surfaces by other authors conducted at the same setup. ${ }^{33}$ The Ce $4 \mathrm{~d}$ spectra were measured with a photon energy of $450 \mathrm{eV}$. The photoionization cross section for the $4 \mathrm{~d}$ level undergoes a Cooper minimum at lower photon energies, ${ }^{34,35}$ hence a higher photon energy has to be chosen. At $450 \mathrm{eV}$ photon energy we expect to probe the whole of the $\mathrm{CeO}_{x}$ island structures in our experiment. The $\mathrm{O} 1 \mathrm{~s}$ spectra were recorded at $650 \mathrm{eV}$ photon energy, the $\mathrm{C} 1 \mathrm{~s}$ and $\mathrm{Rh} 3 \mathrm{~d}$ spectra at $435 \mathrm{eV}$. The spectra presented were normalized to the background at the low binding energy side. Deconvolution of the $\mathrm{O} 1 \mathrm{~s}$ and Rh $3 d_{5 / 2}$ spectra was done using a Doniach-Šunjić profile and a Shirley-type background (linear for $\mathrm{O} 1 \mathrm{~s}$ ). The binding energy scale was calibrated to the Fermi edge of the Rh substrate.

\subsection{Temperature measurement}

During preparation of the oxide film the temperature was measured by a type- $\mathrm{K}$ thermocouple spot-welded to the side of the rhodium crystals, which were heated by electron bombardment from the back side. For the photoelectron spectroscopy measurements a type-K thermocouple was pressed by a ceramic piece on the top sides of the hat-shaped crystals, which were placed on a BN heater. During those measurements we expect an error not larger than $\pm 10 \mathrm{~K}$ for the temperatures reported in this work.

\section{Results}

For this study two $\mathrm{Rh}(111)$ crystals containing differently sized $\mathrm{CeO}_{2}$ islands were prepared by reactive physical vapor deposition as described in the experimental section. Sample A contained cerium oxide with a total coverage corresponding to $2.0 \mathrm{O}-\mathrm{Ce}-\mathrm{O}$ monolayer equivalents (MLE) while sample B was covered by 0.9 MLE of the oxide. The total coverage was estimated by measuring the attenuation of the Rh KLL signal in AES right after preparation together with the information obtained by STM (see below). The subsequently recorded LEED images (Fig. S1, ESI†) show that the oxide grows in (111) orientation in registry with the substrate, as it has been reported for the growth on numerous transition metal substrates. ${ }^{6}$

The morphology of the oxide deposit was investigated using STM. The oxide preferably nucleates as three-dimensional islands rather than wetting the substrate (Volmer-Weber growth) under the used growth conditions, as it has also been reported in several studies on other metal substrates. ${ }^{26,27,36,37}$ The micrographs in Fig. 1 show oxide islands found on the respective samples (additional images are comprised in Fig. S2, ESI $\dagger$ ). Fig. 1(a) shows a large triangular island of sample A of more than $100 \mathrm{~nm}$ in diameter, grown at $1030 \mathrm{~K}$. The height profile reveals an initial step height of about $0.95 \mathrm{~nm}$ corresponding to three O-Ce-O trilayers. On top of these first layers several non-closed layers formed, which consist of smaller islands. The height of the island
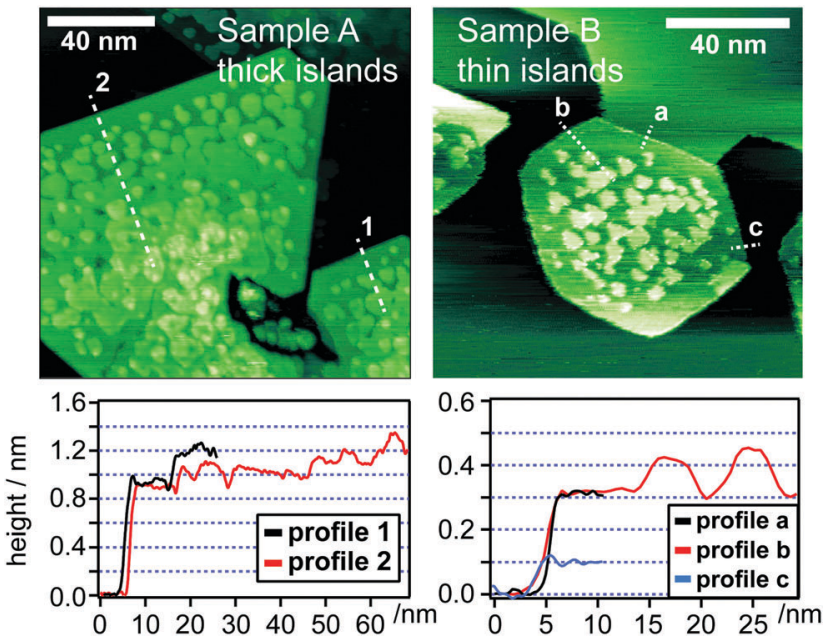

Fig. 1 STM images of ceria islands grown on Rh(111). Left: Sample A: large triangular island grown at $1030 \mathrm{~K}$. The height profiles below show, that the initial step is three $\mathrm{O}-\mathrm{Ce}-\mathrm{O}$ trilayers high. Smaller structures nucleate on top up to 5-6 trilayers in total height. Right: Island grown at $830 \mathrm{~K}$. The base of the island is only one trilayer high, as the profiles indicate. A second layer has started to nucleate. Imaging conditions: $600 \mathrm{mV}$ sample bias, $600 \mathrm{pA}$.

increases toward its center and up to 5-6 layers in maximum height can be observed. The smaller islands found on sample $B$ (Fig. 1(b)) are of hexagonal shape and less than $100 \mathrm{~nm}$ in diameter. The height of the island in Fig. 1(b) is one tri-layer, with a second layer nucleating on top. The amount of the second layer observed on the islands varies, and some islands have larger sections covered by a complete second layer (see Fig. S2, ESI $\dagger$ ). The apparent height of additional layers of the oxide appears lower than the expected value of about $3 \AA$ due to reduced tunneling for thicker layers of $\mathrm{CeO}_{2}$. The apparent height is further a function of the tunneling bias as has been reported for biases below $1 \mathrm{~V}$ for ceria grown on $\mathrm{Pt}(111){ }^{36}$

Given the signal attenuation in AES and the estimated average island heights from STM, it can be deduced that both samples exhibit a comparable amount of uncovered Rh surface ( $40 \pm 2.5 \%$ for the thin and $35 \pm 5 \%$ for the thick islands). The same is inferred by the intensities of the diffraction spots in LEED, which show comparable intensity for oxide and substrate spots, respectively, in both cases. We will come back to the amount of exposed Rh surface when discussing the PES results. In the following, we will refer to the large islands of samples A as 'thick islands' while the islands in sample B will be referred to as 'thin islands'.

\subsection{Thermal reduction}

To follow the change in stoichiometry during annealing of the oxidized $\mathrm{CeO}_{2}$ structures of sample A (thick islands), we measured $\mathrm{Ce} 4 \mathrm{~d}$ spectra while heating the sample up to $920 \mathrm{~K}$ ( $890 \mathrm{~K}$ for the thin islands) in a stepwise fashion. Fig. 2 shows the Ce $4 \mathrm{~d}$ spectra before (bottom) and after (top) thermal reduction of both samples. The middle panel of Fig. 2 shows the evolution of the spectra during reduction of the thick islands. 


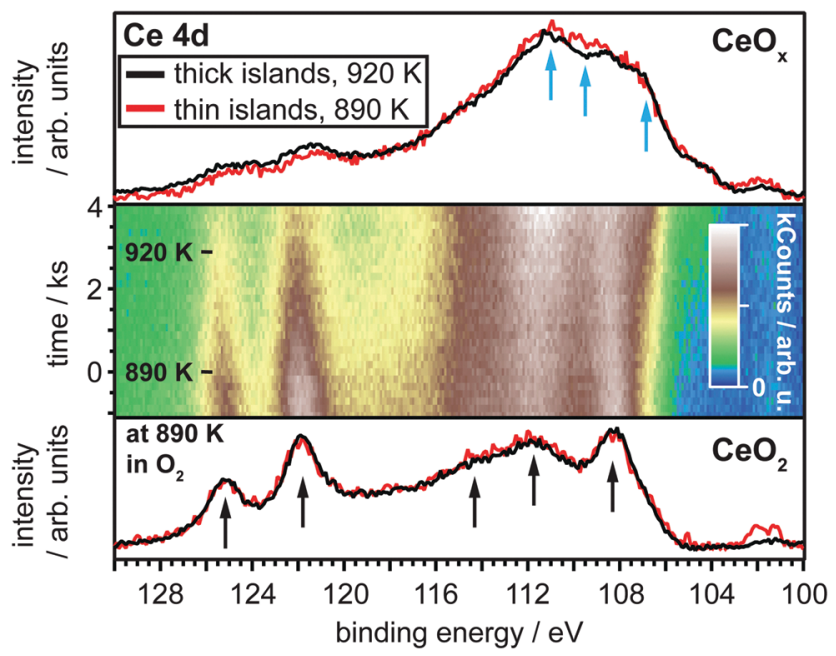

Fig. 2 Bottom: Ce 4d spectra recorded after annealing the ceria structures in oxygen. Arrows point to features indicative of $\mathrm{Ce}^{4+}$. Middle: $2 \mathrm{D}$ plot of individual $\mathrm{Ce} 4 \mathrm{~d}$ spectra of the thick islands recorded while heating the sample. Top: Spectra recorded after the thermal reduction. Blue arrows indicate features characteristic for $\mathrm{Ce}^{3+}$.

The bottom two spectra before the reduction were measured in the presence of $1.3 \times 10^{-5} \mathrm{hPa}$ oxygen. They exhibit typical features associated with the presence of $\mathrm{Ce}^{4+}$ (indicated by arrows). Especially the two peaks at 122 and $125 \mathrm{eV}$ stand out and are thought of to mainly originate from the Ce $4 \mathrm{~d}^{9} \mathrm{O} 2 \mathrm{p}^{6} 4 \mathrm{f}^{0}$ final state configuration ${ }^{38}$ and hence are expected to decrease in intensity with a decrease in $\mathrm{Ce}^{4+}$ content in the oxide. The spectra of the oxidized thick and thin islands look virtually identical, inferring an identical oxidation state. It has to be noted, that previous studies of the growth of thin ceria layers on $\mathrm{Rh}(111)$ report a stoichiometry of $\mathrm{CeO}_{1.84}$ for the first trilayer and a stoichiometry close to $\mathrm{CeO}_{2}$ for a film of mainly two trilayers thickness. ${ }^{20,22}$ The higher concentration of $\mathrm{Ce}^{3+}$ ions in the first $\mathrm{O}-\mathrm{Ce}-\mathrm{O}$ trilayer is thought to either originate from a charge transfer from the metal substrate to the cerium ions or by actual oxygen vacancies. However, the cited measurements were done in ultrahigh vacuum, while an oxygen ambient was present during the acquisition of the bottom two spectra in Fig. 2. The oxygen probably hinders the apparent reduction of the very thin oxide layers and may explain why both our films show an identical Ce $4 \mathrm{~d}$ spectrum for the thin and thick islands in Fig. 2. We hence assume both, thick and thin islands to be $\mathrm{CeO}_{2}$, i.e. close to $100 \% \mathrm{Ce}^{4+}$, in our case.

To reduce the ceria islands thermally, the temperature was held at $870 \mathrm{~K}$ after the cleaning treatment and the oxygen was pumped out of the chamber. The final pressure during the following heat treatment was reached after 3-4 spectra, i.e. $\approx 500-700 \mathrm{~s}$, and stabilized at $1.3-3.0 \times 10^{-9} \mathrm{hPa}$. The temperatures were held constant and only increased at the points indicated in the middle section of Fig. 2, while Ce $4 \mathrm{~d}$ spectra were acquired. Increasing the temperature to $890 \mathrm{~K}$ and $920 \mathrm{~K}$, respectively, took 1-2 spectra, corresponding to $175-350 \mathrm{~s}$. The temperature was kept below $900 \mathrm{~K}$ for the thinner islands and close to $900 \mathrm{~K}$ for the thicker islands to avoid decomposition of the oxide, which has been reported to occur above this temperature range. ${ }^{18,20}$

Heating of the ceria structures clearly leads to a decrease of the intensity of the $\mathrm{Ce}^{4+}$ related components. At the same time the intensity of features between 107-112 eV increases, indicating an increasing $\mathrm{Ce}^{3+}$ concentration. (corresponding data for the thin islands in Fig. S4, ESI $\dagger$ ) The samples were heated until no changes were observed any longer in the $4 \mathrm{~d}$ spectra. The top two spectra in Fig. 2 show the result after the samples have been heated to the respective temperature for at least $30 \mathrm{~min}$. The spectra, again, appear similar, though the thin islands are likely reduced a bit more, indicated by the lower intensity between 119-126 eV and the slightly higher intensity between 108-112 eV.

In order to determine the average stoichiometry of the oxide structures during thermal reduction a linear combination of the most reduced and most oxidized spectrum can be applied to describe every intermediate spectrum. The method has been successfully applied to Ce $3 \mathrm{~d}$ spectra ${ }^{39,40}$ and we describe our approach for the Ce $4 \mathrm{~d}$ spectra in detail in the ESI. $\dagger$ The results of the evaluation are compiled in Fig. 3 showing the obtained $x$ in $\mathrm{CeO}_{x}$ on the right ordinate and the weight of the $\mathrm{CeO}_{2}$ spectrum in the linear combination on the left ordinate (for details see $\mathrm{ESI} \dagger$ ). As is evident from Fig. 3, the reduction starts at $870 \mathrm{~K}$ for the thin islands, i.e. right after the oxygen has been closed off, while a temperature of $890 \mathrm{~K}$ is necessary for an observable reduction to commence in case of the thick islands. A change of the slope of the decrease of $\mathrm{Ce}^{4+}$ is visible at $890 \mathrm{~K}$ for the thin islands, which also reach their maximum reduced state after about one hour of annealing time. The thicker islands, however, require a higher temperature and/or a longer time for reduction. The maximum reduced state reached in our experiment is about $\mathrm{CeO}_{1.62}$ after more than $60 \mathrm{~min}$ of total annealing time.

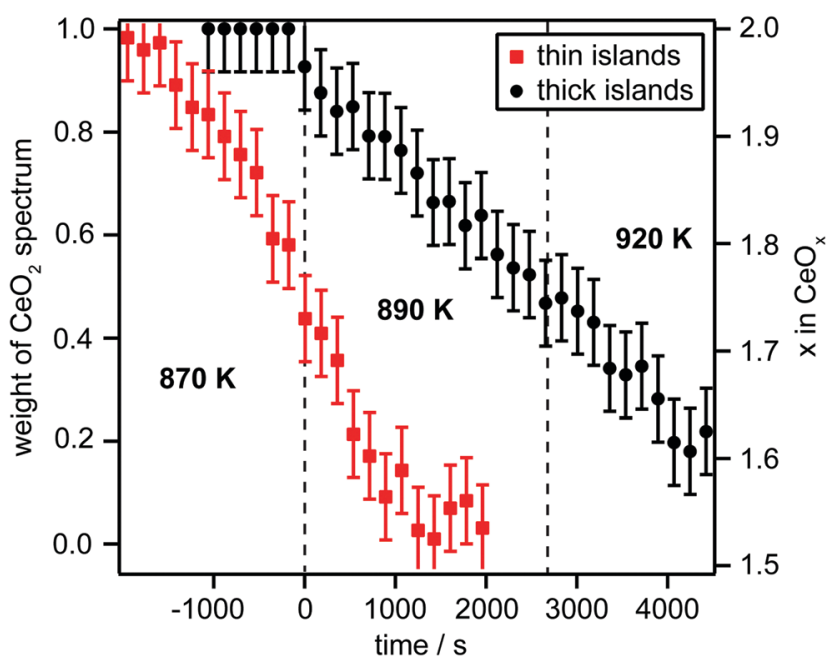

Fig. 3 Result of fitting series of $\mathrm{Ce} 4 \mathrm{~d}$ spectra measured during thermal reduction of the thin (red squares) and thick (black circles) ceria islands. Left ordinate: weight of the $\mathrm{CeO}_{2}$ reference spectrum in the final fit. Right ordinate: resulting stoichiometry for $\mathrm{CeO}_{x}$ with error bars \pm 0.04 . The time is arbitrarily set to 0 where the thick islands start to reduce. The thin islands were completely reduced at $893 \mathrm{~K}$ and not heated further. 


\subsection{Re-Oxidation by $\mathrm{CO}_{2}$}

To investigate to which extent the ceria nanostructures can be re-oxidized when exposed to carbon dioxide, two sets of experiments where performed. In a set of static experiments, the reduced ceria structures were first exposed to $10^{-5} \mathrm{hPa} \mathrm{CO}_{2}$ at $370 \mathrm{~K}$ and then a set of spectra was recorded (still in $\mathrm{CO}_{2}$ ambient) when no changes were observed any longer (steady state). Subsequently, the temperature was increased stepwise up to $870 \mathrm{~K}$ and the same set of spectra was measured at each step. In a dynamic experiment, Ce $4 \mathrm{~d}$ spectra where measured continuously while the reduced ceria structures where exposed to $10^{-5} \mathrm{hPa} \mathrm{CO}_{2}$ at a specific temperature.

Static experiment. After the reduction experiment described above the samples were cooled down to $370 \mathrm{~K}$, which was chosen over room temperature as a starting temperature to avoid a long waiting time to achieve thermal equilibrium. Once the temperature was stabilized, $1.3 \times 10^{-5} \mathrm{hPa} \mathrm{CO}_{2}$ were dosed into the chamber. The samples were kept at the specific temperature for about 20-30 min, until no further changes were discernible in measured Ce $4 \mathrm{~d}$ spectra. A full set of O 1s, C 1s, Rh 3d, and Ce $4 \mathrm{~d}$ spectra was measured during $\mathrm{CO}_{2}$ exposure, before the temperature was increased to the next step.

Before the discussion of information gained from the individual core levels we consider the resulting stoichiometry extracted from the Ce $4 \mathrm{~d}$ spectra (Fig. 4). After cooling down to $370 \mathrm{~K}$ the reduced $\mathrm{CeO}_{x}$ structures exhibited a stoichiometry of $\mathrm{CeO}_{1.63}$ and $\mathrm{CeO}_{1.61}$ for the thick and thin islands, respectively. That means that a slight re-oxidation already took place when cooling down the sample to $374 \mathrm{~K}$ likely caused by residual $\mathrm{O}_{2}$ gas in the chamber background. Another cause of the observed re-oxidation could be residual water in the chamber background. Studies of water adsorption on partially reduced ceria have, however, not shown a pronounced re-oxidizing effect and, in

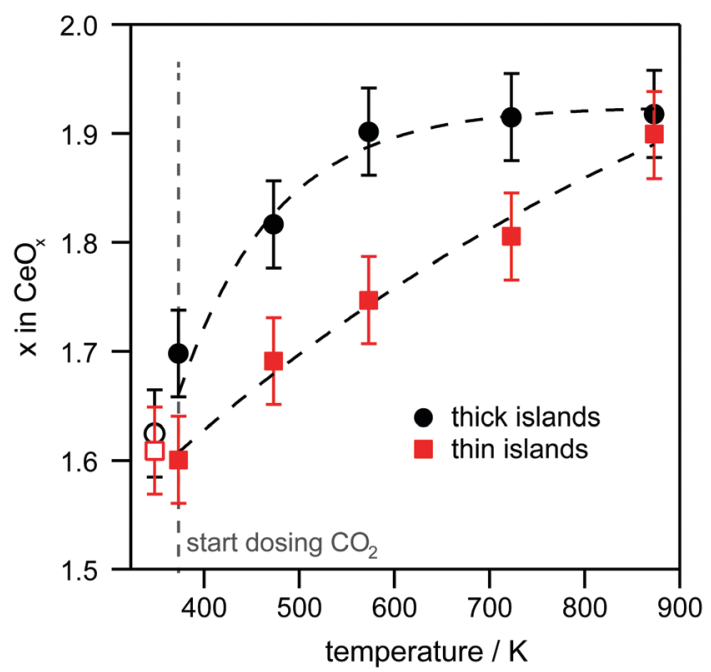

Fig. 4 Stoichiometry ( $x$ in $\mathrm{CeO}_{x}$ ) as a function of sample temperature during $\mathrm{CO}_{2}$ exposure. Data points left of the dashed line were measured at $370 \mathrm{~K}$ in UHV. Filled circles: resulting stoichiometry for the thick islands at the temperature given. Red squares: stoichiometry for the thin islands. Dashed curves are inserted to guide the eye. some cases, even an increase in the $\mathrm{Ce}^{3+}$ signal. ${ }^{41}$ The formation of two $\mathrm{O}-\mathrm{H}$ groups upon water dissociation on the oxide surface should not lead to a higher $\mathrm{Ce}^{4+}$ content. Furthermore, O-H groups can be stable up to $500 \mathrm{~K}$ on reduced ceria, ${ }^{16}$ implying that a re-oxidizing effect of water should only be expected at elevated temperature. We can, however, not completely rule out a slight re-oxidizing effect of residual water in case of our strongly reduced ceria islands.

After dosing $1.3 \times 10^{-5} \mathrm{hPa} \mathrm{CO}_{2}$ the thick islands oxidize on average to $\mathrm{CeO}_{1.70}$ while the oxidation state of the thin islands stays virtually unchanged. Increasing the temperature to $470 \mathrm{~K}$ leads to oxidation for both kinds of islands to $\mathrm{CeO}_{1.82}$ for the thick and $\mathrm{CeO}_{1.70}$ for the thin islands. Already at $570 \mathrm{~K}$ the thick islands reach a value of $\mathrm{CeO}_{1.90}$ which is not increasing further with increasing temperature. The thin islands are oxidized to just $\mathrm{CeO}_{1.75}$ at $570 \mathrm{~K}$ and $\mathrm{CeO}_{1.81}$ at $720 \mathrm{~K}$ before they also reach a value close to $\mathrm{CeO}_{1.90}$ at $870 \mathrm{~K}$.

Striving to obtain a better understanding of the difference in the temperature dependence of the oxidation of the two different $\mathrm{CeO}_{x}$ island types, we next consider the other core levels, starting with the $\mathrm{C}$ 1s spectra, Fig. 5. At $370 \mathrm{~K}$ small amounts of carbon close to the detection limit are observed on both samples, which have likely been collected from the chamber background when cooling down the samples after reduction. When dosing $1.3 \times 10^{-5} \mathrm{hPa} \mathrm{CO}_{2}$ at $370 \mathrm{~K}$ three signals can be resolved in the $\mathrm{C} 1 \mathrm{~s}$ spectra of both surfaces. The leading peak is located at $286.3 \mathrm{eV}$ and caused by $\mathrm{CO}$ adsorbed on the exposed Rh surface, clearly showing that $\mathrm{CO}_{2}$ dissociates. The $\mathrm{CO}$ related signal exhibits a very similar intensity on both surfaces inferring that both samples contain a comparable area of exposed Rh surface, already assumed earlier. The leading peak further exhibits a small shoulder at the low binding energy side, which cannot clearly be assigned but likely stems from CO bound to three-fold hollow or bridge sites. ${ }^{42}$ A signal at $290.0 \mathrm{eV}$ likely originates from carbonate species $\left(\mathrm{CO}_{3}{ }^{2-}\right){ }^{43,44}$ The signal is slightly less intense on the sample

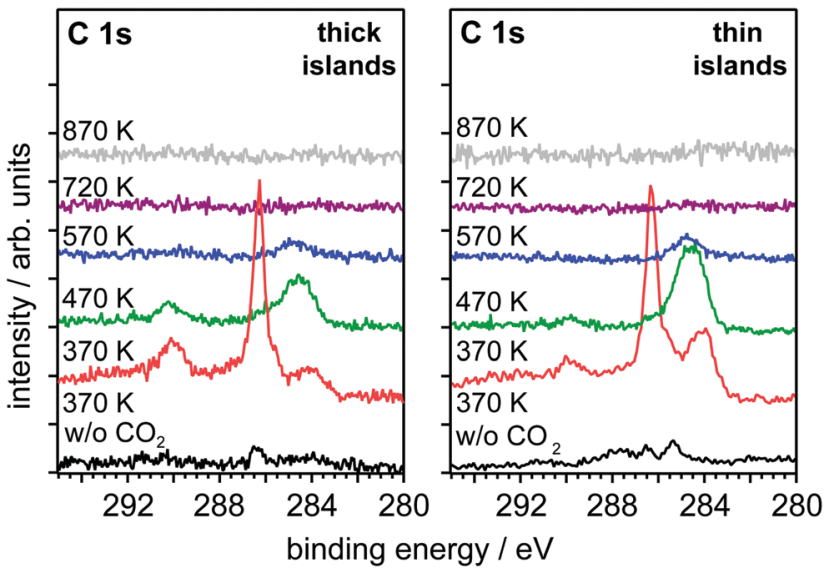

Fig. 5 Carbon 1s spectra during $\mathrm{CO}_{2}$ exposure. Left: Spectra for the thick oxide islands. Right: Spectra for the thin islands. The samples were kept for 20-30 min at the temperature indicated before a spectrum was recorded. The bottom spectrum was measured at $370 \mathrm{~K}$ in UHV after cooling down from the thermal reduction. 
containing the thin islands. The third signal at the lowest binding energy, $284.1 \mathrm{eV}$, falls in the range between $\mathrm{CH}_{x}$ and $\mathrm{C}$ species. ${ }^{45}$ The signal is more intense for the thin islands, suggesting, that the respective carbon species is bound to the perimeter of the oxide islands. Given that about the same surface area is covered by oxide on the both samples, as the results presented so far show, more perimeter sites are expected to be available on the sample containing smaller islands, thus leading to the higher intensity for the signal at $284.1 \mathrm{eV}$ in case of the thin islands.

Increasing the sample temperature to $470 \mathrm{~K}$ leads to a nearly complete disappearance of the CO signal. Only slight intensity is remaining at the position of the former shoulder of the $\mathrm{CO}$ signal. The results match reports in literature in which $\mathrm{CO}$ desorption has been observed at temperatures close to $500 \mathrm{~K}$ on $\mathrm{Rh}(111) .{ }^{46,47}$ The signal located at the lowest binding energy increases in intensity and shifts to higher binding energy when the temperature is increased. This can be interpreted as hydrogenation to $-\mathrm{CH}_{x}$ species and eventually $-\mathrm{CH}_{3}$, as already observed for ceria islands on copper exposed to an $\mathrm{CO}_{2} / \mathrm{H}_{2}$ mixture. ${ }^{45}$ In our case, the hydrogen would have to originate from the chamber background or $-\mathrm{OH}$ groups formed on the ceria by spurious amounts of water (e.g. formed at the hot filament of pressure gauges during oxygen dosage). As Fig. 4 shows, only limited re-oxidation is observed at $470 \mathrm{~K}$. A possible explanation for the limited re-oxidation is thus that the sites at which oxygen could enter the ceria islands, the perimeter sites, are still partially blocked by carbon species, significantly hindering the re-oxidation through that channel. When the temperature is increased further to $570 \mathrm{~K}$ the $-\mathrm{CH}_{x}$ species start to desorb from the surface and at the same time a further re-oxidation of the ceria islands is observed in both cases. At $720 \mathrm{~K}$ and onwards no carbon is detected anymore on either sample.

Selected spectra of the Rh 3d core level are compiled in Fig. 6 (full set in Fig. S6, ESI $\dagger$ ). The spectra recorded at $370 \mathrm{~K}$ in UHV can be deconvoluted into two peaks originating from a bulk and a surface related signal which are marked B and S in Fig. 6. The binding energy difference of the two components is $0.4 \mathrm{eV}$, i.e. slightly smaller than the reported value of $0.5 \mathrm{eV}$ for clean $\mathrm{Rh}(111) .{ }^{48}$ The relative integral intensity of the surface and bulk components is shown in panel (c) of Fig. 6 for each annealing step. Before dosing $\mathrm{CO}_{2}$ the intensity of the surface component is about $16 \%$ larger for the sample containing the thin islands, i.e. that sample may exhibit a respective larger amount of exposed $\mathrm{Rh}$ surface, which aligns well with the estimations made earlier based on AES and STM.

Dosing $\mathrm{CO}_{2}$ at $370 \mathrm{~K}$ significantly attenuates the surface components in both spectra (middle section of Fig. 6(a) and (b)). At the same time a slight increase in intensity of the bulk signal occurs. This can be explained by CO adsorption on the $\mathrm{Rh}$ surface essentially resulting in a shifted surface signal moving underneath the bulk signal as described in ref. 42 . The experimental resolution is, in our case, not large enough to discern this extra contribution. The explanation by adsorbed $\mathrm{CO}$ is in line with the $\mathrm{C} 1 \mathrm{~s}$ spectra showing a large signal
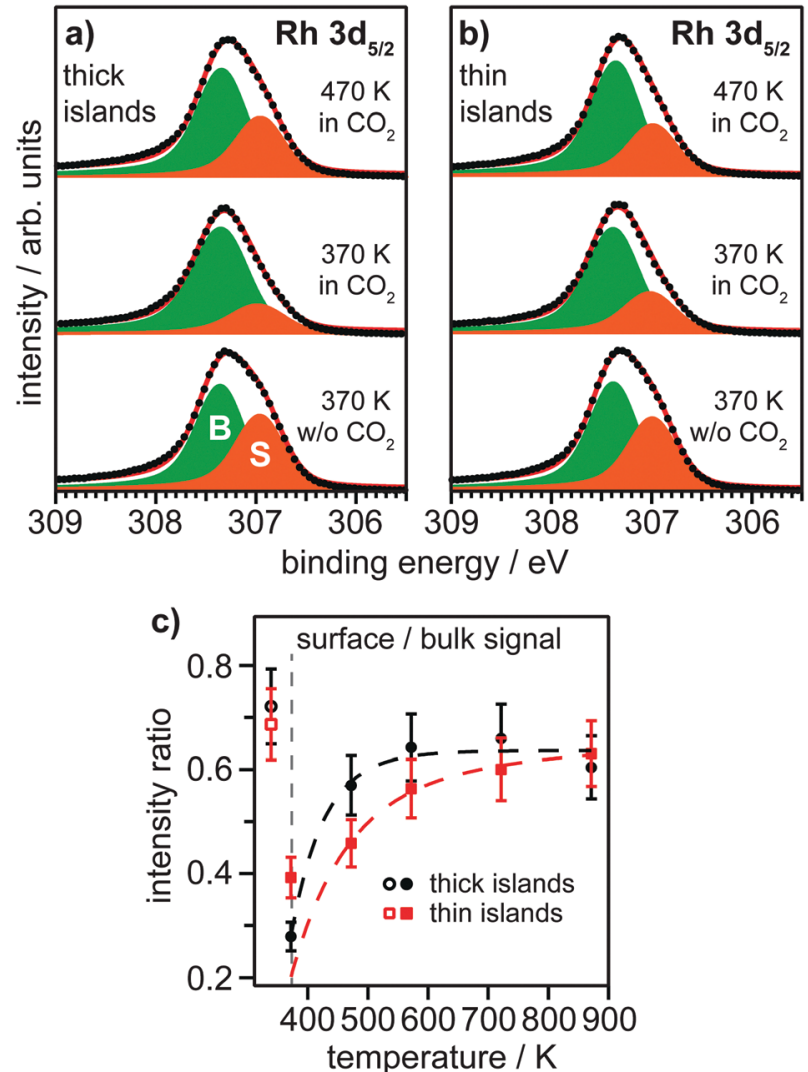

Fig. 6 Selected $\mathrm{Rh} 3 \mathrm{~d}_{5 / 2}$ spectra recorded right before and during $\mathrm{CO}_{2}$ exposure. (a) Sample A containing thick $\mathrm{CeO}_{x}$ islands and (b) sample $\mathrm{B}$ containing thin islands. The signals are deconvoluted into two peaks originating from bulk atoms (green, labeled B) and surface atoms (orange, labeled S). (c) Integral intensities of the surface components as a function of sample temperature. Data points left of the dashed line are measured at $370 \mathrm{~K}$ before dosing $\mathrm{CO}_{2}$. The dashed curves are inserted as a guide to the eye.

attributed to $\mathrm{CO}-\mathrm{Rh}$ at this temperature. However, more surface signal appears to remain for sample B (thin islands). Increasing the temperature to $470 \mathrm{~K}$ leads to a recovery of the surface component, also matching the loss of CO-Rh signal, i.e. desorption of $\mathrm{CO}$, in the carbon spectra. At $570 \mathrm{~K}$ there is a further recovery of the surface component on sample $\mathrm{B}$ while only an insignificant increase occurs for sample A (thick islands). No significant changes occur within the margin of error of the experiment when increasing the temperature further. Finally, the surface to bulk ratio levels out at a similar value for both surfaces.

As the last part of the static experiment we turn to the $\mathrm{O} 1 \mathrm{~s}$ spectra, of which a selection is presented in panels (a) and (b) of Fig. 7 (full set in Fig. S7 in ESI $\dagger$ ). The deconvolution of spectra measured at $370 \mathrm{~K}$ prior to $\mathrm{CO}_{2}$ exposure reveals three components. The most intense component is located at $529.9 \mathrm{eV}$ and $529.7 \mathrm{eV}$ for the thick and thin islands, respectively. The signal originates from oxygen atoms of the oxide lattice. The binding energy values agree with reported values for reduced ceria. ${ }^{20}$ The component at the highest binding energy $(532.0 \mathrm{eV})$ in the two bottom spectra of Fig. 7 originates from species collected when cooling the sample down to $370 \mathrm{~K}$ after thermal reduction. A likely assignment are $\mathrm{OH}$ groups formed from 

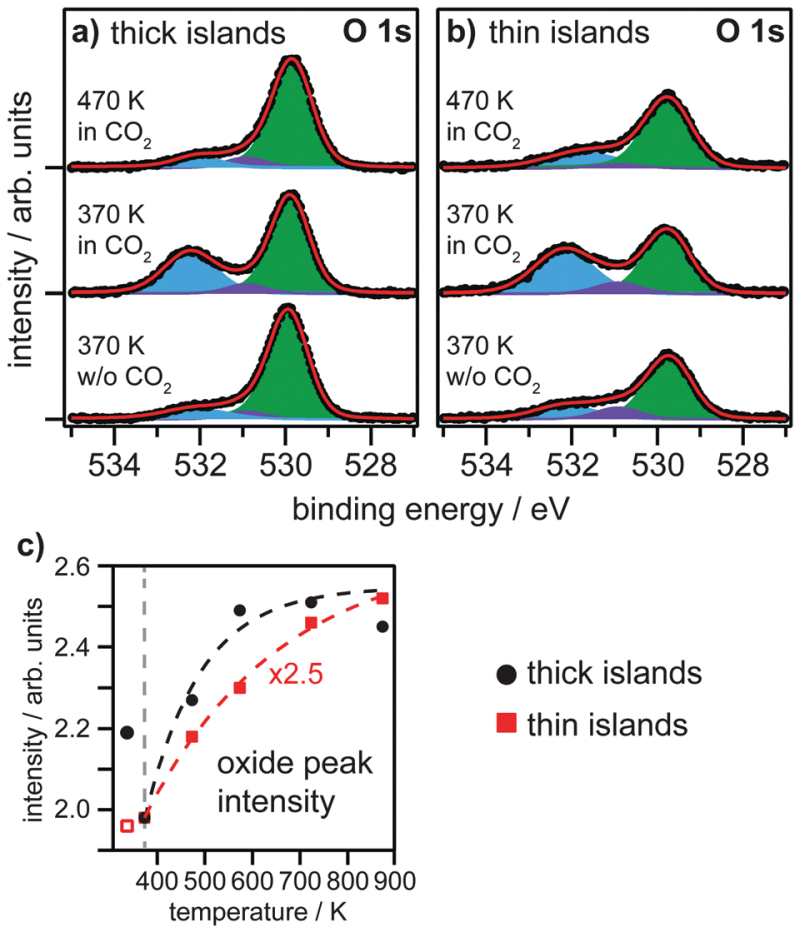

thick islands

thin islands
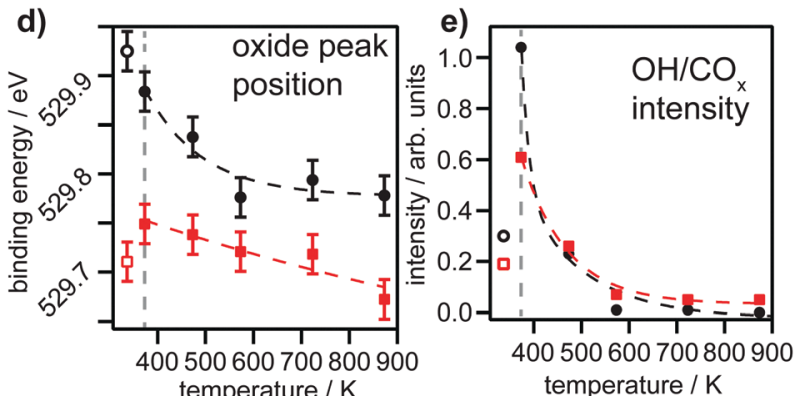

Fig. 7 Selected oxygen 1s spectra recorded before and during $\mathrm{CO}_{2}$ exposure. Spectra are deconvoluted into three peaks. Green: oxide related peak; light blue: $\mathrm{OH} / \mathrm{CO}_{3}{ }^{2-}$; purple: island perimeter/interface. Overall spectra for the (a) thick and (b) thin islands behave similar and corresponding to observations made in the $\mathrm{C} 1 \mathrm{~s}$ spectra. (c) Integral intensity of the oxide signal as a function of sample temperature. (d) Position of the oxide peak as function of sample temperature. (e) Integral intensity of the $\mathrm{OH} / \mathrm{CO}_{x}$-related component (blue).

water in the chamber background. Hydroxyl groups have been reported to be present up to $500-700 \mathrm{~K}$ on stoichiometric and reduced ceria, respectively. ${ }^{41}$ To obtain a satisfying fit of the spectra a third component located at $531 \mathrm{eV}$ was inserted. This signal has previously been interpreted as stemming from Rh-O-Ce entities. ${ }^{20}$ We hence also assign this signal to stem from $\mathrm{Rh}-\mathrm{O}-\mathrm{Ce}$ entities, likely located at the perimeter and interface sites of the ceria islands, because the component is observed under all conditions throughout the whole experiment.

Dosing $\mathrm{CO}_{2}$ at $370 \mathrm{~K}$ leads to a signal at $532.2 \mathrm{eV}$ on both samples. Given the results presented so far, the signal must comprise contributions from $\mathrm{CO}$, carbonate, and probably also a minor amount of hydroxyl groups, which cannot be resolved in the $\mathrm{O} 1 \mathrm{~s}$ spectra. The same signal decreases again when heating to $470 \mathrm{~K}$, in line with the decrease of $\mathrm{CO}$ and $\mathrm{CO}_{3}{ }^{2-}$ intensity in the $\mathrm{C}$ 1s spectra. Accordingly, no significant signal is observed anymore at $570 \mathrm{~K}$ and onwards at $532 \mathrm{eV}$ as is also shown in panel (e) in Fig. 7 comprising the integral intensity of the component.

A closer look at the integral intensity of the oxide related $\mathrm{O} 1 \mathrm{~s}$ signal reveals a temperature dependent increase of the intensity during $\mathrm{CO}_{2}$ exposure which follows the same trends observed for the stoichiometry extracted from the Ce $4 \mathrm{~d}$ spectra. In other words: the intensity of the oxide signal of the thick islands reaches a maximum already at $570 \mathrm{~K}$ while the temperature needs to be increased up to $870 \mathrm{~K}$ for the thin islands to reach a comparable intensity. In general, information about the oxidation state of the oxide structures may also be extracted from the binding energy position of the oxide $\mathrm{O} 1 \mathrm{~s}$ signal. Usual values, if reported, range from $530 \mathrm{eV}$ for $\mathrm{Ce}_{2} \mathrm{O}_{3}$ to $529 \mathrm{eV}$ for $\mathrm{CeO}_{2}$. The absolute binding energies, however, vary with substrate used and film thickness studied, ${ }^{16,20,22}$ while a comprehensive summary of binding energy positions and underlying effects is up to now still lacking. Considering the shift of the position of the oxide related signal upon re-oxidation with $\mathrm{CO}_{2}$, we only observe a shift of -0.15 and $-0.08 \mathrm{eV}$ for the thick and thin islands, respectively (Fig. 7(d)). A shift on the $\mathrm{O} 1 \mathrm{~s}$ signal as small as $0.3 \mathrm{eV}$ between $\mathrm{CeO}_{2}$ and $\mathrm{Ce}_{2} \mathrm{O}_{3}$ has, for instance, also been reported for films on $\mathrm{SrTiO}_{3}$, while usual values on thicker ceria films on metal substrates, measured in UHV, are in the range of up to $1 \mathrm{eV}$. The general trend, however, which we observe for the shift in binding energy of the oxide peak during re-oxidation with $\mathrm{CO}_{2}$ follows all other results reported above. For the thick islands the oxide peak shifts downward by $0.15 \mathrm{eV}$, indicating oxidation, and reaches a maximum shift at $570 \mathrm{~K}$. For the thin islands the starting binding energy is lower and the downward shift observed is close to the margin of error of the evaluation (shift about $0.08 \mathrm{eV}$ ).

Dynamic experiment. In order to follow the dynamics, a second re-oxidation experiment was done, starting at $570 \mathrm{~K}$ instead of $370 \mathrm{~K}$, in $1.3 \times 10^{-5} \mathrm{hPa} \mathrm{CO}_{2}$. Ce $4 \mathrm{~d}$ spectra were measured continuously during the whole experiment. Fig. 8 compiles the

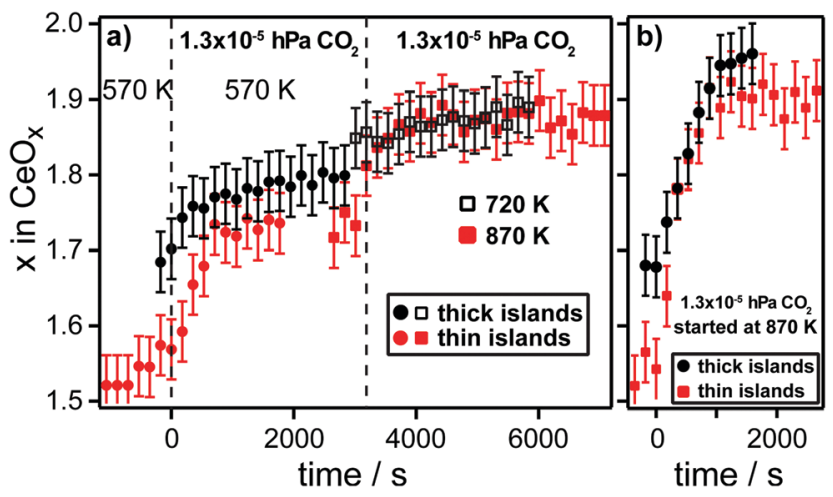

Fig. 8 Stoichiometry extracted from the Ce $4 d$ spectra recorded during the dynamic experiment. Black circles and open squares represent values obtained from the thick islands, and red circles and squares values from the thin islands, respectively. At time $0 \mathrm{~s} \mathrm{CO}_{2}$ was dosed into the chamber. (a) After reduction the sample is cooled to $570 \mathrm{~K}$ and then $\mathrm{CO}_{2}$ is dosed for $3000 \mathrm{~s}$ before the temperature is increased to $720 \mathrm{~K}$ (thick islands) and $870 \mathrm{~K}$ (thin islands), respectively. (b) Samples were kept at $870 \mathrm{~K}$ after reduction and $\mathrm{CO}_{2}$ directly dosed at that temperature. 
stoichiometry extracted by fitting each Ce $4 \mathrm{~d}$ spectrum with a linear combination of spectra from the most oxidized and reduced spectrum obtained by thermal reduction (see above section). Also in this experiment a slight re-oxidation already takes place while cooling the samples down to $570 \mathrm{~K}$ after reduction, caused by the residual gas in the chamber. Before starting to dose $\mathrm{CO}_{2}$, the thin islands had re-oxidized to $\mathrm{CeO}_{1.57}$ and the thick islands to $\mathrm{CeO}_{1.68}$, which, in both cases, is an offset of +0.05 in $x$ compared to the final values after reduction at 870/920 $\mathrm{K}$.

Dosing $\mathrm{CO}_{2}$ at $570 \mathrm{~K}$ leads to a fairly quick increase of the oxygen content in the thin ceria structures corresponding to $\mathrm{CeO}_{1.74}$ after $700 \mathrm{~s}$ (see red circles in Fig. 8(a)). Further $\mathrm{CO}_{2}$ exposure does not lead to further oxidation. Increasing the temperature to $870 \mathrm{~K}$, which was accomplished within $350 \mathrm{~s}$ corresponding to two measured Ce $4 \mathrm{~d}$ spectra, a stoichiometry of $\mathrm{CeO}_{1.89}$ is reached after a time of $1600 \mathrm{~s}$ $\mathrm{CO}_{2}$ exposure at $870 \mathrm{~K}$. From there on even additional $2500 \mathrm{~s}$ of exposure do not oxidize the thin ceria islands further, in accordance with the static experiment.

After a rather quick oxidation to $\mathrm{CeO}_{1.75}$ within $500 \mathrm{~s}$ at $570 \mathrm{~K}$ the thick islands oxidize further rather slowly within the following $1200 \mathrm{~s}$ up to $\mathrm{CeO}_{1.80}$ (black circles in Fig. 8(a)). The data does not clearly indicate that a final value has been reached after a total $\mathrm{CO}_{2}$ exposure of about $3000 \mathrm{~s}$, which again is in accordance with the static experiment showing that a longer exposure at $570 \mathrm{~K}$ already leads to a final stoichiometry close to $\mathrm{CeO}_{1.90}$ for the thick islands. However, in the dynamic experiment the temperature was increased to $720 \mathrm{~K}$ after $3000 \mathrm{~s}$ $\mathrm{CO}_{2}$ exposure at $570 \mathrm{~K}$. The temperature increase also leads to a nearly immediate increase of the $\mathrm{Ce}^{4+}$ content in the thick islands corresponding to a stoichiometry of $\mathrm{CeO}_{1.84}$ which increases slowly further to $\mathrm{CeO}_{1.89}$ over the course of $2000 \mathrm{~s}$. Both samples end up at the same stoichiometry of $\mathrm{CeO}_{1.90}$ as it has been observed in the static experiment.

In a last experiment, the oxide structures were reduced and then exposed to $\mathrm{CO}_{2}$ directly at $870 \mathrm{~K}$ (Fig. 8(b)). Also in this case the zero in the time scale marks the start of $\mathrm{CO}_{2}$ dosing. For both, thin and thick islands, a steep increase in $\mathrm{Ce}^{4+}$ content is observed. The thin islands stabilize to $\mathrm{CeO}_{1.91}$ after about $850 \mathrm{~s}$ while the thick islands reach $\mathrm{CeO}_{1.94}$ within $1000 \mathrm{~s}$ (again note that one spectrum takes $175 \mathrm{~s}$ to measure).

\section{Discussion}

The thermal reduction in UHV shows that the thin islands of one to two O-Ce-O trilayer thickness are more reducible than thicker islands. This effect also has been described for ceria islands and films on $\mathrm{Pt}(111){ }^{24}$ The authors of ref. 20 observe the onset of reduction already at about $770 \mathrm{~K}$ while a thicker film (10 ML) only contains one monolayer equivalent of $\mathrm{Ce}^{3+}$ ions even after heating to $1020 \mathrm{~K}$. The higher reducibility of the thin islands in ref. 20 is reasoned by a decrease in the surface oxygen vacancy formation energy. Furthermore, the authors report a change in the electronic structure of ultra-thin ceria films on Pt which are caused by their dimensionality and the proximity of the platinum substrate. Also Castellarin-Cudia et al. report a difference in the electronic structure of the first ceria trilayer grown on $\mathrm{Rh}(111)$, which is further shown in LDOS calculations. ${ }^{49}$ The calculations in ref. 49 reveal a nonzero electron density in the gap, while the results also show that the second $\mathrm{O}-\mathrm{Ce}-\mathrm{O}$ trilayer already screens the substrate effectively. Our experimental results suggest that the increased reducibility is an effect that scales with film thickness to some extent. The thicker islands, which are four to six $\mathrm{O}-\mathrm{Ce}-\mathrm{O}$ trilayers in height, clearly exhibit a lower reducibility while they are still more reducible than thicker films as, for example, in ref. 24. It has to be noted that PES is an averaging technique. Especially regarding the thick islands it cannot be excluded that thinner parts, as they are shown by STM to exist at the outer areas of the islands, exhibit a lower oxygen content, while the thicker areas are re-oxidized above $\mathrm{CeO}_{1.90}$. Nevertheless, the trends when going from smaller, thinner toward larger, thicker ceria structures are evident. A more precise method like resonant PES at the Ce $4 \mathrm{~d}$ edge $\mathrm{e}^{30-32}$ would be necessary to determine the $\mathrm{Ce}^{3+}$ content in the very first layers more accurately. To compare very surface sensitive studies with spectra carrying more information from the lower layers of the oxide seems to be even more important in light of predictions from theory ${ }^{50,51}$ and recent experimental results, ${ }^{52}$ suggesting, that oxygen vacancies at $\mathrm{CeO}_{2}(111)$ surfaces migrate to a subsurface position, while they stay at the surface at other surface orientations. The effect described by the authors in ref. 52 is likely also essential for the activation of $\mathrm{CO}_{2}$ over ceria catalysts and further study is required in this field.

Exposure to $\mathrm{CO}_{2}$ clearly re-oxidized the reduced ceria structures up to $\mathrm{CeO}_{1.90}$. $\mathrm{CeO}_{1.90}$ appears to be an upper limit even when increasing the temperature up to $870 \mathrm{~K}$ in $1.3 \times 10^{-5} \mathrm{hPa}$ $\mathrm{CO}_{2}$. Studies by Matolin et al. showed that closed ceria films on $\mathrm{Cu}(111)$ that have been partially reduced to $\mathrm{CeO}_{1.80}$ can be re-oxidized to $\mathrm{CeO}_{1.90}$ by dosing about $30000 \mathrm{~L} \mathrm{CO}_{2}$ at room temperature. ${ }^{53}$ It is pointed out in ref. 53 that partially reduced ceria(111) surfaces exhibit an intrinsic reactivity towards $\mathrm{CO}_{2}$, evidenced by the fact that re-oxidation occurs in the absence of transition metal particles or hydroxyl groups on the ceria. The upper limit of $\mathrm{CeO}_{1.90}$ of the re-oxidation was explained by a decrease in oxygen vacancy formation energy that occurs when the oxygen content in the ceria increases. In our experiment it takes an equivalent dose of about $8000 \mathrm{~L}$ at $570 \mathrm{~K}$ until a rather stable stoichiometry is reached for both island types. From there on, the oxidation state increases only slowly for the thick islands but even after a total dose of $30000 \mathrm{~L}$ it has only a stoichiometry of $\mathrm{CeO}_{1.80}$, as shown in the dynamic experiment. An increase of the sample temperature is needed to speed up the re-oxidation process. An even higher total dose, compared to the static experiment, of approximately $50000 \mathrm{~L}$ (a third each at $370 \mathrm{~K}, 470 \mathrm{~K}$, and $570 \mathrm{~K}$ ) leads to $\mathrm{CeO}_{1.90}$ at $570 \mathrm{~K}$. Thus, the total $\mathrm{CO}_{2}$ dose required to reach a stoichiometry of $\mathrm{CeO}_{1.90}$ below $570 \mathrm{~K}$ is much higher compared to the dose needed for a continuous cerium oxide film at room temperature. ${ }^{53}$ However, at $870 \mathrm{~K}$ sample temperature a much lower dose of $10000 \mathrm{~L}$ is sufficient to reach $\mathrm{CeO}_{1.90}$ for both kinds of islands. Hence we conclude that in our experiment the re-oxidation is facilitated 
through two pathways: (1) the decomposition of $\mathrm{CO}_{2}$ on the oxide itself leads to direct re-oxidation as described in ref. 53, but appears to be less effective below $\approx 600 \mathrm{~K}$. If this were, however, the main process, we would expect a re-oxidation already at the lower temperatures of our study, i.e. $370 \mathrm{~K}$ and $470 \mathrm{~K}$, respectively. We do not observe significant re-oxidation at those temperatures. Hence we propose that (2) in the main process $\mathrm{CO}_{2}$ decomposes on the exposed Rhodium surface providing atomic oxygen species that are able to diffuse to the ceria islands and are incorporated into the oxide lattice. It has been debated under which conditions $\mathrm{CO}_{2}$ dissociates on rhodium. ${ }^{54-56}$ We do observe a signal in the $\mathrm{C} 1 \mathrm{~s}$ spectrum that can be assigned to $\mathrm{CO}-\mathrm{Rh}(111)$, and it disappears at temperatures typical for CO desorption. ${ }^{46}$ Hence we conclude that $\mathrm{CO}_{2}$ indeed dissociates to $\mathrm{CO}$ and $\mathrm{O}$ on the Rh surface. As it has been demonstrated in ref. 21 , reduced ceria islands can be re-oxidized by chemisorbed oxygen on Rhodium above $400 \mathrm{~K}$, i.e. when the temperature is high enough for the oxygen to become mobile and being incorporated into the ceria islands. However, even at $470 \mathrm{~K}$ we do not observe the maximum re-oxidation in the static experiment. As the $\mathrm{C} 1 \mathrm{~s}$ spectra reveal, this is caused by CO adsorbed on the rhodium surface, likely hindering the diffusion of oxygen to the islands and/or the adsorption of further $\mathrm{CO}_{2}$ to a significant extent. Once the CO has left the rhodium surface and the island-Rh perimeter sites, which happens between 400 and $570 \mathrm{~K}$, the re-oxidation of the oxide proceeds. The results discussed above reflect the characteristics of a bifunctional catalyst. The $\mathrm{CeO}_{x} / \mathrm{Rh}$ surface is capable of activating (splitting) $\mathrm{CO}_{2}$ at rather low temperatures below $400 \mathrm{~K}$. Temperatures above $400 \mathrm{~K}$ then facilitate the migration of oxygen to the reduced oxide islands while the remaining $\mathrm{CO}$ is potentially available for further reaction with, e.g. hydrogen to form products like methanol or methane, as seen in other model systems. ${ }^{6,11,57}$ However, a reactivation step is required to keep the $\mathrm{CeO}_{x}$ islands in a partially reduced state for oxygen capture.

The adsorbed $\mathrm{CO}$ does not, however, explain the different temperatures needed to oxidize the thick and thin islands to $\mathrm{CeO}_{1.90}$. From both surfaces the carbon species desorb in the same temperature range. But only when reaching $870 \mathrm{~K}$ have the thin islands been oxidized to the same extent as the thick islands. Furthermore, the $\mathrm{C}$ 1s and $\mathrm{Rh} 3 \mathrm{~d}$ spectra indicate that both surfaces exhibit a comparable amount of free $\mathrm{Rh}$ surface area, which implies that in both cases comparable amounts of oxygen are supplied for the re-oxidation of the $\mathrm{CeO}_{x}$ structures. From the results discussed we conclude that the higher reducibility observed for the thin islands is an intrinsic property. Our data does not provide further insight into the underlying effects, but it is likely that an electronic effect, as discussed in ref. 24 and 49, caused by the proximity to the metal substrate is at the origin of the higher reducibility and, in turn, the higher temperatures required for the re-oxidation observed for the thin islands.

\section{Conclusions}

In this article we have shown that ceria nanostructures deposited on a rhodium substrate can be re-oxidized by exposure to
$\mathrm{CO}_{2}$ after initial thermal reduction. Not only does the reducibility but also the re-oxidizability by $\mathrm{CO}_{2}$ depend on the thickness of the ceria deposit. Ultrathin ceria islands are found to reduce at lower temperatures and are more difficult to re-oxidize while islands of several $\mathrm{O}-\mathrm{Ce}-\mathrm{O}$ trilayers in thickness require higher temperature for reduction and are more easily re-oxidized. Consistent with previous reports on the reducibility of ceria ultrathin films this effect appears to be caused by the proximity to the metal substrate, and we have demonstrated here that it applies to the re-oxidation by $\mathrm{CO}_{2}$ as well. The maximum oxidation state of strongly reduced $\mathrm{CeO}_{x}$ achievable by re-oxidation using $\mathrm{CO}_{2}$ is close to an average stoichiometry of $\mathrm{CeO}_{1.90}$, even with the assistance of an exposed rhodium surface, and thus lower than the maximum achieved by molecular oxygen. The reason for this result partly remains an open question and calls for further studies.

The $\mathrm{CO}_{2}$ mainly acts a an oxygen source for the re-oxidation of the $\mathrm{CeO}_{x}$ islands. Nevertheless, the $\mathrm{CeO}_{x} / \mathrm{Rh}$ system efficiently removes oxygen from $\mathrm{CO}_{2}$, transforming it to $\mathrm{CO}$ at rather low temperatures. In the presence of hydrogen, these CO species can potentially undergo further reactions to form industrially relevant products like methane, as was recently reported for a $\mathrm{Rh} / \mathrm{CeO}_{x}$ powder catalyst. ${ }^{57}$

The possibility to tune the reducibility of small oxide deposits by controlling the structure's dimensionality and materials combination appears especially interesting in view of small oxide deposits on transition metals in form of nanoparticles or -porous structures, so called inverse catalysts or in janus or dumbbell like particles in which both, metal and oxide, are nano-sized. ${ }^{58}$ Furthermore, the inverse configurations of thin oxide layers covering metal particles or structures are likely of importance for a variety of present and future catalytic systems. In general, obtaining an understanding of the interaction of $\mathrm{CO}_{2}$ with different surface orientations of pure and doped ceria films, also at conditions more relevant to catalytic applications, remains an essential step towards the rational design of catalysts for $\mathrm{CO}_{2}$ utilization.

\section{Conflicts of interest}

There are no conflicts of interest to declare.

\section{Acknowledgements}

The authors thank Ethan J. Crumlin for experimental help at beamline 9.3.2 and thank the whole staff at the Advanced Light Source for their assistance. This research used resources of the Advanced Light Source, which is a DOE Office of Science User Facility under contract no. DE-AC02-05CH11231. Funding for this project was provided by the Röntgen-Ångström Cooperation and the Knut-and-Alice-Wallenberg-Foundation (grant 2015.0058). AS further thanks the ADMIRE research school at Lund University for financial support. 


\section{References}

1 A. Trovarelli and P. Fornasiero, Catalysis by ceria and related materials, Imperial College Press, 2nd edn, 2013.

2 T. Montini, M. Melchionna, M. Monai and P. Fornasiero, Chem. Rev., 2016, 116, 5987-6041.

3 A. Rangaswamy, P. Sudarsanam and B. M. Reddy, J. Rare Earths, 2015, 33, 1162-1169.

4 F. P. Leisenberger, S. Surnev, G. Koller, M. G. Ramsey and F. P. Netzer, Surf. Sci., 2000, 444, 211-220.

5 J. A. Rodriguez, P. Liu, J. Graciani, S. D. Senanayake, D. C. Grinter, D. Stacchiola, J. Hrbek and J. FernándezSanz, J. Phys. Chem. Lett., 2016, 7, 2627-2639.

6 J. A. Rodriguez, D. C. Grinter, Z. Liu, R. M. Palomino and S. D. Senanayake, Chem. Soc. Rev., 2017, 1824.

7 T. Lunkenbein, J. Schumann, M. Behrens, R. Schlögl and M. G. Willinger, Angew. Chem., Int. Ed., 2015, 54, 4544-4548.

8 J. Graciani, K. Mudiyanselage, F. Xu, A. E. Baber, J. Evans, S. D. Senanayake, D. J. Stacchiola, P. Liu, J. Hrbek, J. Fernández Sanz and J. A. Rodriguez, Science, 2014, 345, 546-550.

9 S. Kattel, P. J. Ramírez, J. G. Chen, J. A. Rodriguez and P. Liu, Science, 2017, 355, 1296-1299.

10 R. M. Palomino, P. J. Ramírez, Z. Liu, R. Hamlyn, I. Waluyo, M. Mahapatra, I. Orozco, A. Hunt, J. P. Simonovis, S. D. Senanayake and J. A. Rodriguez, J. Phys. Chem. B, 2017, 122, 794-800.

11 S. D. Senanayake, P. J. Ramírez, I. Waluyo, S. Kundu, K. Mudiyanselage, Z. Liu, Z. Liu, S. Axnanda, D. J. Stacchiola, J. Evans and J. A. Rodriguez, J. Phys. Chem. C, 2016, 120, 1778-1784.

12 T. Jin, Y. Zhou, G. J. Mains and J. M. White, J. Phys. Chem., 1987, 91, 5931.

13 K. Otsuka, Y. Wang, E. Sunada and I. Yamanaka, J. Catal., 1998, 175, 152.

14 S. Bernal, G. Blanco, J. M. Gatica, C. Larese and H. Vidal, J. Catal., 2001, 200, 411.

15 Y. Lykhach, T. Staudt, R. Streber, M. P. A. Lorenz, A. Bayer, H. P. Steinrück and J. Libuda, Eur. Phys. J. B, 2010, 75, 89.

16 D. R. Mullins, Surf. Sci. Rep., 2015, 70, 42.

17 C. Yang, F. Bebensee, J. Chen, X. Yu, A. Nefedov and C. Wöll, Chem. Phys. Chem., 2017, 18, 1874.

18 S. Eck, C. Castellarin-Cudia, S. Surnev, M. G. Ramsey and F. P. Netzer, Surf. Sci., 2002, 520, 173.

19 S. Eck, C. Castellarin-Cudia, S. Surnev, K. C. Prince, M. G. Ramsey and F. P. Netzer, Surf. Sci., 2003, 536, 166.

20 L. H. Chan and J. Yuhara, J. Chem. Phys., 2015, 143, 074708.

21 D. C. Grinter, C. Muryn, A. Sala, C. M. Yim, C. L. Pang, T. O. Mentes, A. Locatelli and G. Thornton, J. Phys. Chem. C, 2016, 11037.

22 L. H. Chan and J. Yuhara, Surf. Sci., 2017, 69.

23 J. I. Flege, J. Höcker, J. T. Sadowski, S. D. Senanayake and J. Falta, Nucleation, morphology, and structure of sub-nm thin ceria islands on Rh(111), Surf. Interface Anal., accepted.
24 G. Gasperi, L. Amidani, F. Benedetti, F. Boscherini, P. Glatzel, S. Valeri and P. Luches, Phys. Chem. Chem. Phys., 2016, 18, 20511.

25 M. Sauerbrey, J. Höcker, M. Wellbrock, M. Schowalter, J.-O. Krisponeit, K. Müller-Caspary, A. Rosenauer, G. Wei, L. Colombi Ciacchi, J. Falta and J. I. Flege, Cryst. Growth Des., 2016, 16, 4216.

26 D. C. Grinter, S. D. Senanayake and J. I. Flege, Appl. Catal., B, 2016, 197, 286.

27 F. Dvořák, O. Stetsovych, M. Steger, E. Cherradi, I. Matolínová, N. Tsud, M. Škoda, T. Skála, J. Mysliveček and V. Matolín, J. Phys. Chem. C, 2011, 115, 7496.

28 S. Tanuma, C. J. Powell and D. R. Penn, Surf. Interface Anal., 2005, 37, 1-14.

29 M. E. Grass, P. G. Karlsson, F. Aksoy, M. Lundqvist, B. Wannberg, B. S. Mun, Z. Hussain and Z. Liu, Rev. Sci. Instrum., 2010, 81, 053106.

30 V. Matolín, M. Cabala, V. Cháb, I. Matolínová, K. C. Prince, M. Škoda, F. Šutara, T. Skála and K. Veltruská, Surf. Interface Anal., 2008, 40, 225-230.

31 V. Matolín, I. Matolínová, L. Sedláček, K. C. Prince and T. Skála, Nanotechnology, 2009, 20, 215706.

32 V. Matolín, J. Libra, M. Škoda, N. Tsud, K. C. Prince and T. Skála, Surf. Sci., 2009, 603, 1087-1092.

33 Z. Liu, T. Duchon, H. Wang, D. C. Grinter, I. Waluyo, J. Zhou, Q. Liu, B. Jeong, E. J. Crumlin, V. Matolin, D. J. Stacchiola, J. A. Rodriguez and S. D. Senanayake, Phys. Chem. Chem. Phys., 2016, 18, 16621.

34 M. Baron, O. Bondarchuk, D. Stacchiola, S. Shaikhutdinov and H. J. Freund, J. Phys. Chem. C, 2009, 113, 6042.

35 J. W. Cooper, Phys. Rev., 1962, 128, 681.

36 P. Luches, F. Pagliuca and S. Valeri, J. Phys. Chem. C, 2011, 115, 10718.

37 B. Kaemena, S. D. Senanayake, A. Meyer, J. T. Sadowski, J. Falta and J. I. Flege, J. Phys. Chem. C, 2013, 117, 221.

38 D. R. Mullins, S. H. Overbury and D. R. Huntley, Surf. Sci., 1998, 409, 307.

39 H. Wilkens, O. Schuckmann, R. Oelke, S. Gevers, M. Reichling, A. Schaefer, M. Baumer, M. H. Zoellner, G. Niu, T. Schroeder and J. Wollschlager, Phys. Chem. Chem. Phys., 2013, 15, 18589.

40 A. Allahgholi, J. I. Flege, S. Thieß, W. Drube and J. Falta, Chem. Phys. Chem., 2015, 16, 1083.

41 Y. Lykhach, V. Johánek, H. A. Aleksandrov, S. M. Kozlov, M. Happel, T. Skála, P. S. Petkov, N. Tsud, G. N. Vayssilov, K. C. Prince, K. M. Neyman, V. Matolín and J. Libuda, J. Phys. Chem. C, 2012, 116, 12103.

42 A. Beutler, E. Lundgren, R. Nyholm, J. N. Andersen, B. Setlik and D. Heskett, Surf. Sci., 1997, 371, 381.

43 S. D. Senanayake and D. R. Mullins, J. Phys. Chem. C, 2008, 112, 9744.

44 S. D. Senanayake, D. Stacchiola, J. Evans, M. Estrella, L. Barrio, M. Pérez, J. Hrbek and J. A. Rodriguez, J. Catal., 2010, 271, 392.

45 Z. Zuo, P. J. Ramírez, S. D. Senanayake, P. Liu and J. A. Rodriguez, J. Am. Chem. Soc., 2016, 138, 13810.

46 L. A. DeLouise and N. Winograd, Surf. Sci., 1984, 138, 417. 47 G. Krenn, I. Bako and R. Schennach, J. Chem. Phys., 2006, 124, 144703. 
48 J. N. Andersen, D. Hennig, E. Lundgren, M. Methfessel, R. Nyholm and M. Scheffler, Phys. Rev. B: Condens. Matter Mater. Phys., 1994, 50, 17525.

49 C. Castellarin-Cudia, S. Surnev, G. Schneider, R. Podlucky, M. G. Ramsey and F. P. Netzer, Surf. Sci., 2004, 554, L120.

50 M. V. Ganduglia-Pirovano, J. L. F. Da Silva and J. Sauer, Phys. Rev. Lett., 2009, 102, 1-4.

51 G. E. Murgida and M. V. Ganduglia-Pirovano, Phys. Rev. Lett., 2013, 110, 246101.

52 C. Yang, X. Yu, S. Heissler, P. Weidler, A. Nefedov, Y. Wang, C. Wöll, T. Kropp, J. Paier and J. Sauer, Angew. Chem., Int. Ed., 2017, 56, 16399-16404.
53 T. Staudt, Y. Lykhach, N. Tsud, T. Skála, K. C. Prince, V. Matolín and J. Libuda, J. Catal., 2010, 275, 181.

54 L. H. Dubois and G. A. Somorjai, Surf. Sci., 1980, 91, 514.

55 D. W. Goodman, D. E. Peebles and J. M. White, Surf. Sci. Lett., 1984, 140, L239.

56 H. A. C. M. Hendrickx, A. P. J. M. Jongenelis and B. E. Nieuwenhuys, Surf. Sci., 1985, 154, 503.

57 N. M. Martin, P. Velin, M. Skoglundh, M. Bauer and P.-A. Carlsson, Catal. Sci. Technol., 2017, 7, 1086-1094.

58 S. Jiang and S. Granick, Janus Particle Synthesis, SelfAssembly and Applications, The Royal Society of Chemistry, 1st edn, 2012. 